\title{
ASSENTAMENTOS INFORMAIS LATINO-AMERICANOS: CONSIDERAÇÕES SOBRE O MELHORAMENTO DE BAIRROS E AS HABITAÇÕES SOCIAIS
}

\author{
Camila Ribeiro Cardoso dos Santos \\ Doutoranda em desenvolvimento local e \\ cooperação internacional, Universidade de Valência, \\ Pesquisadora no Instituto de Estudios Urbanos y Territoriales da Pontifícia \\ Universidad Católica de Chile
}

\begin{abstract}
RESUMO - Este artigo apresenta as características dos assentamentos informais na América Latina, assim como a descrição e limitações dos dois principais tipos de políticas utilizadas para enfrentar a questão na Região, sendo elas, as políticas de melhoramento de bairro e os projetos de habitação social. Estas ações representam alternativas para incrementar a qualidade de vida e reduzir a vulnerabilidade urbana dos setores pobres em meio a cidades segregadas. Foram descritas as características e motivações que giram em torno às alternativas habitacionais das classes marginalizadas de todos os segmentos do mercado formal, envolvendo os aspectos da pobreza urbana e as restrições impostas pelo mercado imobiliário. Para alcançar os objetivos propostos, se fez uso de uma revisão dos fenômenos e de seus mecanismos, abrangendo trabalhos realizados por autores dedicados ao tema na Região.
\end{abstract}

Palavras chave: pobreza urbana; mercado habitacional; informalidade; políticas urbanas

\section{LATIN AMERICAN INFORMATIVE SETTINGS: CONSIDERATIONS ON THE IMPROVEMENT OF NEIGHBORHOODS AND SOCIAL HABITATIONS}

\begin{abstract}
This article presents the characteristics of informal settlements in Latin America, as well as the description and limitations of the two main types of policies used to address the issue in the region, such as neighborhood improvement policies and social housing projects. These actions represent alternatives to increase the quality of life and reduce the urban vulnerability of poor sectors in segregated cities. The characteristics and motivations that revolve around the housing alternatives of the marginalized classes of all segments of the formal market, have been described, involving aspects of urban poverty and the restrictions imposed by the real estate market. In order to reach the proposed objectives, a review of the phenomena and their mechanisms was conducted, including works by authors dedicated to the theme in the Region.
\end{abstract}

Keywords: urban poverty; housing market; informality; urban policies

\section{INTRODUÇÃO}

Para compreender o estado das artes das cidades de América Latina é, antes de mais nada, importante entender os processos que incidiram na urbanização da Região, no qual, as relações sociais são marcadas pela desigualdade e as bases econômicas são submissas e vulneráveis às lógicas produtivas globais. As estruturas econômicas, sociais e institucionais rurais foram transferidas para o contexto urbano, ou seja, as cidades foram se constituindo a partir da urbanização de sociedades sumamente desiguais procedentes do campo. A consequência deste processo implicou sobre a composição de grupos urbanos dispares com a preponderância da 
pobreza. Ao longo do tempo, a pobreza urbana adquiriu maior complexidade e atualmente assume perfis heterogêneos que variam em todos os níveis territoriais.

No espaço, a desigualdade é refletida por meio de distintas formas de separação que levam em conta vários fatores. A dinâmica de ocupação das cidades assume formas desiguais e que, geralmente, obedecem a critérios que se adequam às amenidadesatreladas aos recursos urbanos existentes, sejam eles naturais ou construídos. Em sociedades capitalistas, a vantagem de negociação, em termos de acesso a estes recursos, pertence aos grupos sociais com maiores níveis de renda. As cidades crescem em paralelo com um processo de divisão do espaço devido à conformação de brechas sociais constituídas pelas diferenças de acesso aos serviços, padrões de consumo, marginalidade no mercado de trabalho, entre outros. Deste modo, a cidade dual é um conceito que remete à existência de diferentes padrões de vida, hábitos e de consumo dentro um mesmo espaço urbanizado.

Neste debate, os espaços dos pobres têm características que, geralmente, se associam à precariedade do entorno, à vulnerabilidade dos habitantes, às carências de respaldo institucional e ao baixo capital humano. Este modelo de espaço residencial afeta de maneira decisiva as trajetórias de vida individuais e coletivas dos cidadãos residentes, na região latino - americana, o assentamento informal é a principal expressão do hábitat dos pobres urbanos.

Este artigo descreve as características principais dos assentamentos informais da América Latina, assim como expõem as limitações de dois tipos de políticas utilizadas para enfrentar a questão na Região: as ações de melhoramento de bairro e os projetos de habitação social. Para alcançar este objetivo, se optou por apresentar as contribuições realizada por autores dedicados ao tema no âmbito regional. Este artigo se divide, além desta introdução, em uma revisão sobre os principais aspectos da pobreza urbana e dos espaços que a concentram; e, dos assentamentos informais e de suas políticas na América Latina. Por fim, se apresenta breve resumo dos detalhes dispostos no trabalho.

\section{POBREZA E O ESPAÇO DA POBREZA URBANA}

Como parte integrante das cidades, a pobreza urbana assume características particulares que, em meio aos mercados urbanos mercantilizados, se referem à falta ou à insuficiência de recursos monetários para atender às necessidades cotidianas. A pobreza, por si só, consiste em um fenómeno complexo, ao mesmo tempo em que é a base estrutural de outras características que se interatuame que vão além do aspecto monetário. A pobreza envolve desde o limitado acesso aos bens, serviços e oportunidades até uma maior exposição às situações de violência e de descriminação. Este conjunto de características heterogêneas manifestam-se diariamente e se refletem nas limitações sobre a geração de capacidades individuais com efeitos intergeracionais. 


\begin{abstract}
"La pobreza y la exclusión social afectan directamente las vidas de los ciudadanos y limitan sus posibilidades actuales y futuras de alcanzar un nivel de bienestar adecuado con el nivel de desarrollo del territorio en el que residen (...) esta situación, de convertirse en duradera, induce mayores riesgos de pobreza en el futuro; y sin las adecuadas políticas educativas, sanitarias y de protección social, el riesgo de pobreza se transmite de generación en generación" (Goerlich, 2017, p. 93).
\end{abstract}

A principal especificidade da pobreza urbana reside na indisponibilidade diante da indispensabilidade de recursos monetários para atender às necessidades de reprodução social nas cidades. As restrições de acesso e a qualidade das relações com o mercado de trabalho se destacam como a base da condição de pobreza e, consequentemente, de seus efeitos. Os pobres urbanos, ao lidar mais fortemente com a economia de mercado, estão mais expostos a ela, neste cenário, a magnitude e a estabilidade de rendimentos regulares, capazes de garantir a sobrevivência e o cumprimento dos requisitos de reprodução social nas cidades, se mostram determinantes.

Neste sentido, Ziccardi (2008) destaca a pobreza como um processo complexo de escassez de recursos econômicos, sociais, institucionais e políticos e que está associado, principalmente, às condições de inserção laboral, onde se prevalecem a instabilidade, a informalidade, os baixos salários ea precariedade. A soma destas características atua sobre a dificuldade de efetivar os direitos dentro de cidades mercantilizadas. Nestes contextos, a falta de rendimento se vinculam a outros ciclos de carências urbanas e disseminam os efeitos multiplicadores e interligados por distintas áreas. Ou seja, a ausência ou a fragilidade (instabilidade e precariedade) do vínculo com o mercado de trabalho são fundamentais para explicar desvantagens dos pobres; esses grupos geram, igualmente, inúmeras estratégias de adequação às restrições impostas.

As novas caras do capitalismo, as novas formas de desigualdade e os novos modelos produtivos se refletem, entre outros termos, na aparição de uma nova pobreza urbana, notadamente mais vulnerável e heterogênea que a industrial, compatível com o esgotamento do modelo de bem-estar comandado pelo Estado. As mudanças marcam os novos rumos das regras do jogo determinadas pela globalização e pelo avanço da sociedade do conhecimento, onde a diminuição do horizonte de perspectivas, a relativização do papel do Estado e o avanço neoliberal estruturam novas formas de desigualdades e de vulnerabilidades especialmente agressivas (Wacquant, 2015; Reich, 2007; Davis, 2006; Perlman, 2004).

A reestruturação econômica incide em verdadeiros processos de incremento de vulnerabilidade em meio às mudanças de natureza produtiva e institucional e ao passo que os cidadãos se encontram menos protegidos. No contexto de globalização e de reestruturação produtiva, os marginais não são homogêneos nem quantitativamente nem qualitativamente; as mudanças tecnológicas e as novas exigências de qualificação, somado ao esgotamento do Estado de bem-estar, implicaram no aumento da precariedade laboral, da insegurança, da instabilidade, da 
insuficiência e da fragilidade dos contratos de trabalho. Por meio da flexibilização, se debilitou a principal forma de integração a uma sociedade de consumo: o trabalho.

Em meio a esse panorama e diante do caráter mercantilizado dos mercados urbanos, a limitação ocasionada pela restrição do poder de compra leva a que os pobres se encontrem dentro do grupo mais vulnerável a sofrer processos de exclusão das condições de cidadania dentro das cidades. Existe uma correlação entre a concentração de pobreza e a maior incidência de marginalidade e de exclusão social. Nos espaços de pobreza, as melhorias nas condições urbanísticas e os benefícios sociais são mais lentos, assim como persiste-se a concentração de fatores de riscos que costumam determinar expectativas individuais vinculadas ao fracasso educacional e laboral.

Em termos urbanísticos, os mecanismos de exclusão urbana se vinculam ao acesso deficitários a bens de consumo coletivo, ou seja, à habitação e ao entorno. A Nações Unidas (2010), por meio do programa ONU-Hábitat, estende a definição de assentamentos precários, como aquele onde um indivíduo ou um grupo de indivíduos vive, se não conta com uma ou mais das seguintes condições: habitação resistente (capaz de suportar as condições físicas e naturais exógenas);espaço suficiente para viver (máximo de três pessoas dividindo um quarto); acesso à água tratada (que pode ser obtida sem a realização de um esforço extremo); acesso à boas condições sanitárias, em especial referente aos banheiros; e, segurança de propriedade que assegure o não desalojo forçado.

A segregação urbana, que surge a partir das diferenças de capacidade de acesso ao mercado de trabalho, nos ambientes dos mais pobres se expressa pelas condições de desvantagens e pela dificuldade de acesso aos serviços e às infraestruturas. A estas razões, se somam maiores níveis de fracasso escolar, menos oportunidades de emprego, maior exposição a situações de violência e de dependência de substâncias tóxicas, descriminação racial, contra as mulheres, contra as crianças, entre outros. Estas áreas de miséria com graves problemas sociais são consequência da explosão demográfica e insuficiência em meio ao desenvolvimento espontâneo dos espaços de pobreza (Hernández et al, 2014; Aaron, 2008; Maricato, 2003). Em síntese, os bairros urbano-marginais são retraduções espaciais das diferenças econômicas e sociais (Wacquant, 2007), somado aos atributos de desvantagens físicas, ligados aos déficits urbanos e monetários.

O estigma, a ideia do isolamento social e a perspectiva do gueto moderno (Wancquant, 2015) emergem como fatores especialmente desfavoráveis e fortes na garantia da manutenção de ciclos viciosos de marginalidade e de exclusão. Trata-se do capital relacional delimitado por uma rede de sociabilidade restritiva, onde os pobres interatuam com pobres em áreas dominadas pela pobreza. $\mathrm{O}$ isolamento fomenta espécies de condutas alternativas às 
predominantes na cidade como um todo. As dimensões simbólicas vão além do hábitat imediato e as desvantagens se inserem em um marco ainda maior com a presença de elementos subjetivos ligados aos símbolos preponderantes em cidades capitalistas, mercantilizadas, segregadas e classistas. As imagens expressam a realidade percebida pelos habitantes, onde se misturam elementos concretos e abstratos.

Neste sentido, o status se relaciona com o lugar que se ocupa na hierarquia socioeconômica e se refere ao conjunto de relações sociais de poder no contexto destas cidades e destas sociedades capitalistas (Donat, 2018). As percepções construídas relacionam espaços, sujeitos e condutas, de modo que se conformam as aberturas ou as resistências de contato ou convivência entre os grupos sociais. A aversão à pobreza, e a todo o que ela representa, incide em notórios processos de isolamento social dos pobres urbanos.

As conotações da proximidade (positiva e/ou negativa), as relações estruturadas no território (sociais, afetivas, identitárias, históricas), sejam no bairro, na rua ou em qualquer delimitação espacial, exercem uma importante influência nas práticas cotidianas dos habitantes (Lazo y Calderón, 2014). As experiências de aproximação envolvem ativos afetivos, econômicos, sociais, políticos e culturais que são essenciais para a construção e o desenvolvimento das pessoas.

Si el hábitat contribuye a formar el habitus, este hace lo mismo con aquel, a través de los usos sociales, más o menos adecuados, que induce a darle (Bourdieu, 2002, p.123).

É importante observar que, em termos espaciais, a ideia de exclusão ou de marginalidade não se relaciona estritamente com a perspectiva do gueto, que assume contornos ainda mais radicais ao incorporar uma legitimação formal e institucional. Wacquant (2004) destaca que um espaço é considerado um gueto ao constituir-se de quatro elementos: o estigma, o limite, o confinamento espacial e o encapsulamento institucional. Neste caso, o paralelismo institucional é o sintoma de isolamento espacial inflexível.

\footnotetext{
"El gueto denota un área urbana restricta, una red de instituciones ligadas a grupos específicos y una constelación cultural y cognitiva (valores, formas de pensar o mentalidades) que implican tanto el aislamiento socio-moral de una categoría estigmatizada cuanto el truncamiento sistemático del espacio y de las oportunidades de vida de sus integrantes" (Wacquant, 2004, p.155).
}

Para o autor, os bairros habitados por setores pobres (as favelas brasileiras, os ranchos venezuelanos ou os campamentos no Chile) que são espaços reconhecidos como núcleos de abandono e desorganização, não são nada mais que bairros pobres de classe trabalhadora que tem laços muito definidos tanto com a indústria como com os bairros valorizados, aos quais oferece mão de obra para os serviços cotidianos.

Na América Latina, a formação desses espaços guardauma estreita relação com a atuação do setor imobiliário e do capital financeiro da Região, onde, existe uma

\begin{tabular}{lllll}
\hline REVISTA ECONOMIA POLÍTICA DO DESENVOLVIMENTO & Maceió - AL & V.5 N.7. & JUNHO/2018 & P.1-21
\end{tabular}


especialização em atender às camadas de renda mais altas (Maricato, 2010). O mercado imobiliário formal seleciona os residentes de acordo com as condições de pagamento, estabelecendo os preços ao nível do grupo com maior capacidade. A ausência ou a insuficiência de marcos reguladores do mercado imobiliário permite que ele atue como protagonista das decisões que envolvem o desenvolvimento urbano das cidades, inclusive nos projetos de habitações de interesse social, que costumam contar com um amplo apoio de subsídios do Estado. Duhau (2013) ressalta que quando as diferenças de preços entre os mercados (formal e informal) são significativas, a abertura entre ambos é menor e, consequentemente, a segregação tenderá a ser mais marcada. A liberdade de atuação do mercado imobiliário na Região eleva os níveis de segregação das cidades.

Diante destas características, as camadas de mais baixo poder de compra são excluídas do mercado formal e se adequam, ocupando informal ou ilegalmente os espaços rejeitados por ele. Estes espaços costumam estar localizados em áreas que apresentam riscos de acidentes naturais, estão longe dos centros das cidades ou carecem de dotações infraestruturais. Convém destacar que a parcela da população que não pode ter acesso ao mercado formal/legal é, também, a mais vulnerável às mudanças de natureza política, econômica, institucional ou urbanística passíveis de influenciar os interesses do setor imobiliário, das classes dominantes ou do próprio Estado. Geralmente, o entorno dos pobres na cidade mercantilizada é caracterizado pela acumulação de carências e de vulnerabilidades de distintas naturezas.

Não obstante, o "hábitat dos pobres" ou das classes mais pobres compreendem um conjunto de experiências que transcendem os assentamentos precários, englobando, também, os projetos públicos de baixo custo, a habitação campesina ou habitação alugada em áreas centrais das cidades (Connoly, 2015). O desenvolvimento das tecnologias de telecomunicação e das redes de transportes tiveram um importante papel sobre as formas e a localização do hábitat popular, ampliando as possibilidades de localização dos núcleos de pobreza em áreas dispersas que passaram a ser integradas mais facilmente às cidades. Distintos autores apontam a marcada tendência de periferalização ${ }^{1}$ da pobreza nas metrópoles latino-americanas, concentrada cada vez mais nos limites das cidades (Miranda, 2017; Aguilar y López, 2016; Winchester, 2008;Janoschka, 2002).O atual cenário das metrópoles conta com a presença de espaços de pobreza em localidades centrais misturadas com periféricas. Estes espaços são heterogêneos, com significativas diferenças em termos de qualidade dos espaços públicos, de serviços urbanos, de organização social, qualidade das casas e do entorno.

\section{OS ASSENTAMENTOS INFORMAIS}

\footnotetext{
${ }^{1}$ Expressão que se refere ao movimento de expulsão das classes pobres às periferias localizadas nos limites das cidades. \begin{tabular}{llllll}
\hline REVISTA ECONOMIA POLÍTICA DO DESENVOLVIMENTO & Maceió - AL & V.5 N.7. & JUNHO/2018 & P.1-21 & Página-6
\end{tabular}
} 
Os assentamentos informais ou a cidade informal estão vinculados com o funcionamento das relações socioeconômicas presentes no campo, onde se prevalecia a alta concentração de terras e de riquezas dentro de rígidas estruturas hierárquicas, que foram transferidas ao universo urbano. Os avanços tecnológicos registrados no século XX propiciaram a modernização das atividades produtivas no campo, o que ocasionou um processo de migração em massa de uma população pobre e pouco preparada para se adequar às exigências dos mercados urbanos. Na região latino-americana, as cidades cresceram mais como uma alternativa de sobrevivência e de melhor qualidade de vida, para os indivíduos que saiam do campo, do que pelo desenvolvimento de estruturas produtivas consistentes.

Os assentamentos informais representam a solução imediata diante da necessidade de residência dos grupos excluídos da cidade formal. Sua origem e desdobramentos refletem as continuas respostas adaptativas dos marginalizados de todos os segmentos do mercado imobiliário. A grande magnitude deste fenômeno no âmbito latino-americano se deve, além das condições impostas pelo mercado imobiliário formal, à falta de planejamento urbano, às fragilidades institucionais estatais que costumam estar submetidas aos interesses privados e à baixa capacidade de arrecadação dos estados.

Esses fatores se soma má inexistência de programas de habitação social; à rentabilidade dos mecanismos informais; à limitada disponibilidade de terras habitáveis, que na maioria das vezes está submetida às normas urbanísticas elitistas; ao grau de rigidez normativa do mercado do solo formal, assim como os preços praticados pelo mesmo, que por sua vez, dependem da disponibilidade de terra (Clichevsky, 2007; Smolka, 2003). Jaramillo (2008) afirma que em meio a um grande déficit habitacional, a proibição sem nenhuma outra medida adicional, provavelmente não gerará nenhum efeito positivo, podendo, inclusive, provocar efeitos contrários.

Os assentamentos informais são designados por vários nomes, de acordo com cada país: favelas no Brasil; campamentos no Chile; villas miseria na Argentina; vecindades ou colonias populares no México; ou, ranchos na Venezuela e Guatemala. Esses espaços não obedecem ao conjunto de regras e normas que determinam o ordenamento urbanístico formal e, tão pouco, contam com uma proteção jurídica institucional, embora se localizem e funcionem de forma integrada à cidade formal. Os assentamentos informais são protagonistas do desenvolvimento urbano em muitas urbes da Região, evidenciado por meio de processos de densificação e de expansão das manchas urbanas, guardando as especificidades de ritmo e de predominância de formas de ocupação em cada cidade. A atuação do mercado informal inclui tanto a produção das residências (ocupação do solo e construção) como as transações posteriores.

A formação e a consolidação dos espaços de cidade informal são motivadas pela necessidade, sendo a resposta de uma parcela significativa da sociedade ao problema habitacional. 
Esse processo se deriva das condições de precariedade e da informalidade no mercado de trabalho que inviabiliza o acesso à habitação por meio do mercado imobiliário formal (Di Virgilio, 2015); (Magliano etal, 2013; Camago y Hurtado, 2012; Cravino, 2008). Ou seja, em meio à tendência generalizada de mercantilização dos direitos urbanos que incluem os serviços, os espaços de convivência e o transporte, a cidade informal se estrutura pela parcela de indivíduos que integram os grupos dos excluídos do mercado formal/legal da habitação e do solo.

A conjunção entre a necessidade de residência e a existência de terras ociosas guiaram as lógicas de ocupação das cidades informais, intermediadas, muitas vezes, por um mercado ilegal. O fator econômico exerce o primeiro estimulo na formação dos assentamentos informais. A existência de demanda contribuiu à consolidação gradual dos espaços, sendo comum, também, a presença de mais de um núcleo familiar compartilhando uma mesma residência, representando uma estratégia de economia, baseada nas redes de apoio pessoais (Hernández et al, 2014; Matossian, 2010).

A informalidade urbana se expressa através, basicamente, de duas formas de transgressões às regras formais: em relação aos aspectos de propriedade e ao processo de urbanização. A precária qualidade da urbanização e a ausência de documentos de respaldo influenciam a constituição dos preços, que devem ser inferiores ao da terra urbanizada. Garza (2012) destaca que os fatores de formação dos preços das terras informais costumam ser até 90\% mais barata que a outra. Neste sentido, a demanda do mercado informal está constituída, fundamentalmente, pelas classes desfavorecidas (Di Virgilio, 2015; Duhau, 2013; Garza, 2012), apesar de que existem evidências de que a pobreza não é o único grupo presente na cidade informal (Camargo y Hurtado, 2012; Smolka, 2003).

Se verifica uma relação de dependência entre os mercados formais e informais no sentido de que as restrições nos primeiros (escassez, externalidades, requisitos, rigidez, etc.) atuam como estímulos aos segundos. Além disso, os valores estipulados pelo mercado formal influenciam os limites dos preços praticados pelo informal, onde o preço da terra urbanizada atua como uma fronteira dos preços praticados pelo mercado informal em condições ceterisparibuse desconsiderando a existência de determinantes externos positivos e negativos.

Jaramillo (2008) y Smolka (2003) descrevem a seguinte relação entre ambos mercados: o preço da terra urbanizada nos mercados informais é maior que o da terra bruta mais o custo para habitá-la; ao mesmo tempo, o preço tende a ser menor que o preço mínimo da terra habitada e comercializada nos mercados formais. Resumindo: o preço do solo formal é maior que o informal, que, por sua vez, é maior que o da rural.

Os assentamentos informais se estrutura a partir de ações espontâneas e voluntárias com grande presença de autoconstrução e de autosserviços de água, saneamento e energia, esses 
espaços costumam se localizar em zonas onde o preço do solo é mais barato e onde não existe interesse do mercado imobiliário (Pírez, 2013; Ziccardi, 2008; Avendaño, 2006;Tardín, 2006; Duhau, 2003). O conceito de urbanização inversa Pírez (2016) é aplicado a este modelo particular de cidade, utilizado por para destacar que os processos e atores são diferentes ao da cidade formal, no qual, depois do acesso ao lote, o complemento da urbanização fica a cargo dos próprios adquirentes, seja por meio legais (venda de terrenos sem urbanização prévia) ou ilegais (ocupação clandestina ou invasão).

As residências informais costumam ter pior qualidade construtiva em relação às residências formais, além disso, estes espaços possuem outras características, como os espaços públicos residuais, a inexistência ou precariedade de áreas verdes, os déficits de infraestrutura e a irregularidade fundiária. A cidade informal pode ser interpretada, também, como uma cidade espontânea devido à adaptação ao relevo, ao improviso e à ausência de linearidade; em geral, se tratam de espaços caracterizados por uma elevada densidade demográfica e um alto índice de aproveitamento do solo, onde o ordenamento urbanístico, fora dos parâmetros e das diretrizes estabelecidas, desenha um cenário conflitivo e muitas vezes caótico.

O perfil dos moradores destes espaços é consideravelmente heterogêneo e se diferencia de acordo com países e cidades dentro de um mesmo país, por exemplo, os imigrantes procedentes de países limítrofes se destacam nas urbes de Chile e Argentina, ao mesmo tempo em que os migrantes nacionais se concentram nas metrópoles e os migrantes locais nas cidades de menor porte. Embora esta última tendência tenha sido descrita de um modo geral na ocasião de distintos trabalhos ${ }^{2}$, a atual cidade informal é consideravelmente mais heterogênea que no momento de sua expansão - estimulada pela migração campo-cidade. Paralelamente aos perfis socioeconômicos heterogêneos, se observa o aparecimento de estratos sociais a nível interno, justificados pela presença de comércios locais, trabalhadores mais protegidos pertencentes ao mercado de trabalho formal, à melhoria do nível de renda das primeiras famílias e a existência de atividades ilícitas³ .

A existência de uma hierarquia estruturada pelo poder aquisitivo induz a uma segmentação do mercado imobiliário informal, que atua, igualmente, seguindo as lógicas das estratégias empresariais. Deste modo, é possível observar movimentos migratórios dentro do próprio espaço informal, paralelo ao movimento que vai da cidade informal para a formal, o que pode vir acompanhado de um incremento no padrão financeiro deste público (Pasternak, 2003).

Os atores públicos e privados envolvidos na formação e consolidação dos espaços informais são diversos: o proprietário original do terreno, os loteadores clandestinos, os

\footnotetext{
${ }^{2}$ Ver em Garza (2012); Cravino (2008);

${ }^{3}$ As atividades ilícitas, onde também se classificam os contrabandos, costumam ser bastante lucrativas e representam sentidos de pertencimento e de poder derivado das formas de organização estruturadas hierarquicamente com respeito e lealdade. $\begin{array}{llllll}\text { REVISTA ECONOMIA POLÍTICA DO DESENVOLVIMENTO } & \text { Maceió - AL } & \text { V.5 N.7. } & \text { JUNHO/2018 } & \text { P.1-21 } & \text { Página-9 }\end{array}$
} 
moradores, os movimentos cidadãos, o Estado presente ou omisso, as ONGs, etc. A articulação entre os atores se dá de forma complexa, onde o protagonismo das ações costuma variar de acordo com as distintas etapas de desenvolvimento dos espaços informais. Além de refletir uma opção alternativa do mercado habitacional, nesses espaços se misturam ações que ocorrem ao longo de sua estruturação, das quais envolvem mercados/ sub mercados e processos/sub processos legais e ilegais.

O mercado informal existe e persiste vinculado ao clientelismo político, ao mesmo tempo em que é destacada a importância das redes de relações cotidianas (Di Virgilio, 2015; Jaramillo, 2008; Clichevsky, 2007). A ocupação e a consolidação destes espaços se dão por meio de processos e transações relativamente padronizados, nos quais se destacam: a ocupação/invasão do terreno, a autoconstrução do domicilio e a consolidação progressiva da habitação e do entorno. A ocupação é a etapa inicial do processo e ocorre quando os indivíduos têm acesso ao lote de terreno sem pagar por ele. Monayar (2011) classifica o processo de ocupações em organizadas por agentes individuais e em loteamentos fraudulentos por agentes do mercado do solo. Jaramillo (2008) observa que os indivíduos tentam escolher terrenos nos quais a reação à invasão seja menor (propriedades do estado, com donos desconhecidos ou que apresentem algum problema jurídico). Se os terrenos valem menos, é mais provável que os proprietários se esforcem menos no sentido impor barreiras à invasão.

A autoconstrução representa a prática de adaptação dos pobres às circunstâncias e se refere ao esforço realizado pelos mesmos para empreender um espaço capaz de desenvolver as funções de reprodução relacionadas ao habitar. Os auto construtores substituem um recurso escasso - capital monetário - por outro abundante -a força de trabalho. O período de produção é bastante flexível e a estratégia se centra no melhoramento progressivo, onde é comum a contratação de mão de obra especializada para a realização dos serviços mais complexos, a exemplo da eletricidade e do encanamento (Di Virgilio etal, 2012; Jaramillo, 2008).

Finalmente, a etapa de consolidação do entorno conta com um grande protagonismo das famílias e das redes sociais de apoio através, especialmente, das formas de organizações associativas que realizam tanto o auto abastecimento dos serviços, como as reivindicações por melhorias de infraestruturas junto ao poder público. Observa-se, por tanto, um trabalho continuo de apropriação e modificação do espaço que, progressivamente, opera na construção de um território com menos carências. Em meio a uma trajetória não linear e não circular do processo de construção, surgem a casa e o hábitat, consolidando um espaço social circundante.

Geralmente, os habitantes necessitam arcar com os custos das desvantagens associadas às fragilidades infraestruturais; estes espaços costumam ser mais vulneráveis aos acidentes de construção, riscos ambientais, doenças, entre outros. A principal atratividade do hábitat informal 
reside na flexibilidade tanto de acesso (métodos de pagamento, exigências de garantias e requisitos, etc.), como de construção. Estes territórios estão dotados de elevado grau de liberdade urbanística, o que resulta especialmente importante à medida em que são ajustáveis às estratégias de sobrevivência e às necessidades habitacionais das famílias ao longo do tempo.

A liberdade urbanística permite a continua redefinição dos parâmetros da residência, a readequação às novas necessidades ocasionada por membros adicionais ou por ajustes derivados de negócios executados dentro dos limites da residência (aluguel de partes do domicilio ou pequenos comércios autogestionados). Estas atividades representam fontes de renda alternativas diante das restrições impostas pelo mercado de trabalho e implicam em usos múltiplos do espaço. Os limites internos e externos das casas se ajustam no tempo e de acordo com as necessidades que surgem, assim como obedecem a disponibilidade de recursos financeiros e de mão de obra para a construção.

A tendência temporal acompanha uma trajetória de melhoria das condições de habitabilidade à medida em que avança a consolidação da residência e do entorno. A diversidade de formas construtivas se explica pela autonomia das ações tomadas de maneira individualizada. Se constrói um sistema de intercâmbios e solidariedades promovidos pelas relações de proximidade, identidade e necessidades vivenciadas conjuntamente. As redes sociais são fundamentais para explicar os processos de densificação centrada nos amigos e parentes, desde onde se emergem os sentidos de confiança e de proteção mutua. Por estas redes circulam o capital material e imaterial imprescindível para oferecer respostas às questões cotidianas e se convertem em ativos primordiais de retenção no local.

Ao longo do desenvolvimento dos assentamentos, se circulam informações informais sobre as ocupações de terrenos ou casas sujeitas a melhorias ou ampliações. Além disso, a mudança de material construtivo (substituindo os elementos precários por outros mais resistentes), o improviso de objetos disponíveis e o papel das contribuições familiares e das redes de apoio são aspectos imprescindíveis ao analisar do desenvolvimento desses territórios.

Na América Latina foram identificados processos de densificação com franca tendência ao crescimento vertical, sendomais frequente em assentamentos consolidados perto do centro e das oportunidades de trabalho, enquanto que a expansão horizontal atua na periferia, onde o tamanho dos lotes é maior. Estas propensões foram captadas por: Di Virgilio (2015) para Buenos Aires; Camargo y Hurtado (2012) para Bogotá; y, Smolka (2003) para o conjunto de latino-américa. Juntamente com a expansão, a densificação e a consolidação do hábitat informal, ocorre a complexação das transações mercantis com os arrendamentos e os subarrendamentos (de habitações e de quartos) e a incorporação de atores que utilizam lógicas endógenas nos mecanismos de formação de preços. 
A lógica mercantil permite que haja segmentação entre os preços das transações que ocorrem dentro deste espaço, as diferenças se derivam de externalidades positivas e negativas (localização, excesso de oferta ou de demanda, a competição entre demandantes, as lógicas de proximidade, os custos de transporte, as redes sociais, as condições socioeconômicas e culturais do público em questão, situação jurídica dos terrenos, etc.). $\mathrm{O}$ conhecimento e o acesso às redes informais fundamentadas em critérios de recomendações, de palavra e de contratos estabelecidos "cara a cara". Se tratam de relações baseadas na confiança e nas reciprocidades, mas com uma intrínseca lógica mercantil com ânimo de lucro. Em meio à vulnerabilidade às atitudes oportunistas por não se adequar aos marcos regulatórios, o pertencimento às redes de intercambio e às organizações sociais se constitui de uma ferramenta central para ter acesso a esses mercados (Di Virgilio, 2015; Jaramillo, 2008). Onde o aluguel é a forma mais fácil e rápida para se ter acesso aos assentamentos, não obstante, essa prática não se estende a todos os aspirantes a ocupantes, dado que a exigência de remuneração mercantil exclui aos pobres que não o podem pagar.

Alguns aspectos referentes às transações no mercado informal foram captados por distintas pesquisas na Região, Clichevsky (2007) aponta que a compra ilegal é a forma mais comum de hábitat popular em América Latina; Di Virgilio (2015) afirma que o aluguel informal surge em meio ao esgotamento do solo disponível e a consequente estruturação do mercado informal de compra e venda, valendo tanto para a terra como para a habitação; Briceño-León (2008) destaca que nas zonas com maior centralidade e próximas aos setores de altos níveis de renda existem mais alugueis que em outras regiões; Abramo (2008) observa que o volume e o nível de preços das transações imobiliárias confirmam que elas fazem parte de um mercado regular que modula o acesso à terra urbana nas favelas ${ }^{4}$ consolidadas. Jaramillo (2008) destaca que os autoconstrutores tendem a ter uma ideia aproximada do valor cristalizado da construção (trabalho e recursos monetários), assim como também tem uma ideia de quanto custaria alguma coisa normalmente. E, Cravino (2008) aponta que a ilegalidade ou a extralegalidade das transações imobiliárias se sustentam em uma ordem ou normativa local alternativa e a legitimidade vai se consolidando com seu uso cada vez mais estendido.

Diante da ausência de legitimação da propriedade, as transações se centram na compra e venda, onde se comercializam materiais e a mão de obra utilizada para a construção, enquanto a propriedade do solo continua pertencendo a terceiros; neste processo, os interessados tentam resguardar a documentação escrita.

${ }^{4}$ Este trabalho se refere, especificamente, ao Brasil.

\begin{tabular}{llllll}
\hline REVISTA ECONOMIA POLÍTICA DO DESENVOLVIMENTO & Maceió - AL & V.5 N.7. & JUNHO/2018 & P.1-21 & Página-12
\end{tabular}




\section{MELHORAMENTO DE BAIRROS}

Diante da proliferação dos assentamentos informais, o Estado assumiu posturas que se modificaram ao longo do tempo, embora, geralmente, tenha sido mais inclinado a aceitar a ocupação de terras de escasso valor comercial e más condições físicas e ambientais, onde quase todos assumem o compromisso jurídico e político de proteger a propriedade privada (Pírez, 2013; Clichevsky, 2007). A permissibilidade pública se reflete na dimensão espacial que esta forma de urbanização assumiu na região latino-americana, embora, houvessem mudanças de posturas que obedeceram às conjunturas especificas.

O modelo de gestão e o nível de permissibilidade com relação à cidade informal se ajustaram às estratégias políticas populistas, clientelistas, eleitorais ou por omissão das mesmas, assim como a submissão do papel do Estados nacionais às empresas e aos organismos internacionais. Nos anos 90, houve um aprofundamento dos conflitos entre o Estado e os setores populares, no qual o Estado passou a facilitar as ações do capital imobiliário-financeiro respaldados por processos de privatização e de regularização dos assentamentos irregulares.

A retirada do Estado coincidiu com a participação ativa de organismos de financiamento internacional nos programas urbanos de instituições nacionais, estaduais e municipais, além da aplicação de políticas de descentralização através da reforma do Estado em meio à emergência democrática e a gestão mais próxima aos atores locais. O principal argumento utilizado para esta mudança se centrou na maior busca pela eficiência e eficácia das ações políticas, embora, também, representassem uma maior abertura às práticas clientelistas.

O Estado facilitador, inerente à agenda neoliberal, promoveu a participação de atores governamentais e não governamentais. Se produziu, também, a facilitação do funcionamento dos mercados, a descentralização do estado e o financiamento internacional por meio de organismos econômicos multilaterais, como o Banco Mundial (BM) e o Fundo Monetário (FMI).Com o avanço do liberalismo sobre as cidades, a gestão de serviços urbanos foi transferida, maioritariamente, à incumbência do setor privado e a mercantilização impôs a necessidade de regularização dos serviços, assim como a aplicação das tarifas correspondentes, juntamente ao controle da clandestinidade e a consequente exclusão de usuários que não pudessem pagar.

"En las décadas perdidas - de los sesenta a los ochenta- se dirigieron a la erradicación y el reasentamiento masivo de las comunidades en viviendas públicas del Estado. La crisis de la deuda, la bancarrota de buena parte de administraciones y el conflicto permanente en la región incidieron en la relajación del control sobre los procesos de urbanización informal y, solamente cuando el Estado fue estabilizando sus estructuras de gobierno, se pudo pensar en una integración de las barriadas informales (...) resultaría más barata y menos compleja articular en el conjunto de la ciudad consolidada o formal que retomar políticas de erradicación y posterior reasentamiento en vivienda pública dirigida. Los programas de mejoramiento barrial iniciados en los años ochenta se generalizan a partir de los años noventa, 
sobre todo en las principales ciudades de Brasil, Chile y Argentina, estados con un mayor nivel de descentralización administrativa, fiscal y política que la mayor parte de los estados centroamericanos". (Iglesias y Sánchez, 2013, pg. 30 -31).

Em relação às políticas de regularização, Clichevsky (2003) as classifica em três tipos: as destinadas a regularizar a situação da propriedade; a regularizar a situação urbana ambiental; e, as integrais que articulam as ambas. As cidades dos países latino-americanos foram, ao longo dos anos recentes, objetos de políticas públicas de urbanização através de programas de melhoramento de bairros, liderados por organizações e instituições internacionais e que contaram com desenhos participativos.

Foram implementados programas com caráter corretivo através de distintos instrumentos: leis ou decretos, programas ou projetos. Os projetos integrais, especialmente no Brasil e Colômbia, possuem diversos componentes: infraestrutural, equipamentos urbanos, componentes e acompanhamento social e fortalecimento institucional. É importante destacar que os preços praticados no mercado informal de terrenos também captam de maneira antecipada os incrementos associados aos futuros processos de regularização jurídica e física dos bairros. Por outro lado, as organizações sociais de base realizaram conquistas políticas substanciais e um grande reconhecimento do papel democrático nestes momentos.

Os programas de melhoramento de bairros se compõem por projetos de intervenção que pretendem integrar os espaços de assentamentos informais à cidade formal através da implantação de serviços de água, energia, saneamento, vias de acesso, ajudas à mitigação de riscos ambientais, inclusive por meio de reassentamentos, legalização da propriedade e um componente social. O desenho das propostas de intervenção é centrado na participação cidadã, desde o planejamento e desenho das estratégias até a avaliação posterior à intervenção. Embora tenha contribuído para melhorar a qualidade de vida da população, os projetos não costumam incluir ações de combate à situação de pobreza e indigência que se permanecem depois da urbanização.

Por outro lado e apesar dos impactos positivos, em termos de urbanização e de acesso aos serviços e aos equipamentos, a regularização produziu a readequação cidadã à condição de consumidores com obrigações de pagamentos periódicos pelos serviços, gerando um processo de gentrificação ${ }^{5}$ e novas ocupações de outros locais informais e ausentes de urbanização. Esta tendência foi encontrada por Camargo e Hurtado (2012), onde afirmam que as políticas de legalização da situação de informalidade para melhorar a condição urbana e de propriedade do terreno parecem ter promovidos os processos de gentrificação nos anos 90 . Nesta mesma linha, Smolka (2003) destaca que as políticas de regularização, avaliadas em um

${ }^{5}$ Gentrificação urbana é o fenômeno que afeta um espaço ou bairro pela alteração das dinâmicas da composição do local, valorizando a região e afetando a população de baixa renda. Tal valorização é seguida por um aumento de custos de bens e serviços, dificultando a permanência de antigos moradores de renda insuficiente para sua manutenção no local cuja realidade foi alterada, modificando assim, a estrutura social do local por uma de maior renda.

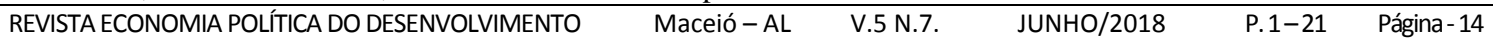


contexto amplo, podem estar contribuindo para agravar o problema que busca remediar ou podem ter efeitos nocivos contraindicados.

A fragilidade socioeconômica predominante nestes espaços os converte em vulneráveis à ocupação por classes imediatamente superiores depois das intervenções urbanas, destacando a necessidade de normativas adicionais de proteção que impliquem sobre o impedimento ou o desestimulo a mudanças a outros espaços informais com todas as suas precariedades. Do mesmo modo, a falta de dados e informações estatísticas formais acerca destes territórios na maioria dos países, assim como a rapidez com que se processam as mudanças, representam impedimentos ao planejamento e à execução de projetos de políticas urbanas mais consistentes, multifocais e sustentáveis.

\section{PROJETOS DE HABITAÇÃO SOCIAL}

A segunda estratégia política se refere à construção de habitações sociais dentro de grandes conjuntos, na qual, se espera reduzir os déficits por meio de subsídios ou reassentamentos de grupos vulneráveis. Esta política se caracteriza pela intervenção direta ou indireta do Estado através da ampliação da oferta, as ações públicas englobam adiantamentos de capital necessário para a construção, assim como a concessão de créditos ao consumidor adquirente e que estão apoiados em empréstimos hipotecários a longo prazo, o que implica em um alto de grau de subsídios, incluindo, também, a oferta de terrenos (Coulomb, 2015; Jaramillo, 2008; Cossio e Tourn, 2005). Este modelo de política vem proporcionando altos níveis de lucro a grandes consórcios imobiliários, grande parte com participação de capital estrangeiro (Hidaldoet al, 2008; Hernadézet al, 2005).

A habitação social se relaciona diretamente com a oferta de terrenos com um baixo valor por unidade de superfície. A escassez do solo, derivada da estrutura de propriedade de terra, extremamente concentrada, foi o principal indutor da localização destes domicílios, expulsando os conjuntos para os limites periféricos das cidades. As construções padrões obedecem aos critérios de economia de escala, destinando menor atenção aos aspectos sociais e ambientais e atuando dentro da lógica de reprodução de interesses econômicos e políticos em meio à consolidação de mecanismos de livre mercado com escassos controles de qualidade.

A partir da década de 1990, a política de habitação social teve grande impacto sobre o desenvolvimento urbano na América Latina. Embora a proposta consista em promover habitações massivas dignas para o público de menor renda, o formato que assumiu ditas políticas protagonizadas pelo mercado imobiliário e tendo o Estado como facilitador normativo, financeiro e institucional - gerou consequências negativas sobre a coesão social, a expansão da mancha urbana e a formação de espaços distantes do centro das cidades. Os conjuntos habitacionais 
costumam ser marcados pela ausência de equipamentos, serviços e áreas de lazer, e que, geralmente, não conseguem integrar um projeto urbano comum, ao mesmo tempo em que representam alternativas concretas para a redução dos níveis de déficit habitacionais.

Os efeitos negativos gerados por este modelo de política foram destacados nos trabalhos de diversos autores, designada como a precariópolis promovida pelo Estado (Hidalgo et al, 2008) no qual se observa que onde foi localizado um projeto habitação social, o índice de desenvolvimento social diminuiu, se manteve ou subiu "levemente". Muitas vezes esses conjuntos geram mudanças negativas no espaço (Morales, 2005). Outros efeitos negativos podem ser vistos na constituição de cidades ou bairros dormitórios dentro de cidades cada vez mais dispersas, onde, os espaços escolhidos se caracterizam por se localizar nos limites da mancha urbanizada e pelo acesso deficitário aos serviços de infraestrutura urbana (Boils, 2008; Coulomb, 2015); na construção em massa de conjuntos dispersos desagregados, já que embora se tenha acesso à habitação em condições de propriedade e do entorno menos vulneráveis, a delimitação espacial está acompanhada de novas desvantagens (Mocteczuma, 2017); as deficiências da urbanização informal que se soma à urbanização formal em um espaço rural-urbano, com núcleos de população isolados (Cruz-Muñoz e Isunza, 2017); o Estado que distribui e acumula a população mais pobre em áreas específicas, os distanciando da capacidade de integração com o resto da cidade (Lunecke, 2016); a distância fora do espaço da cidade - em condição de excluídos ou em "integração excludente" (Bayón, 2015); a política estatal que privatizou o mercado habitacional (especulação imobiliária) e que é uma cópia modesta das zonas residenciais para as classes médias (Arango, 2014); a ausência de comércios e serviços que aguça a separação entre local de residência e o local de trabalho, afeta as formas de viver e utilizar os espaços do conjunto da cidade e das cidades dormitórios - com implicações sobre os laços familiares -, a necessidade de estar fora por jornadas completas e desgastes físicos (Hernández et al, 2005).

As consequências dos projetos têm natureza social, urbana, econômica e ambiental. O isolamento espacial leva intrínseco uma série de desvantagens e aumenta a demanda por serviços e infraestruturas; geralmente, o Estado está condicionado a fornecê-los; nesse processo, os governos municipais enfrentam problemas para responder esta necessidade de forma eficaz. A aliança histórica entre o Estado e os setores do mercado avançaram na construção das cidades por meio de processos de apropriação e de produção do espaço urbano. A cidade se expande e gera dois processos simultâneos: por um lado, a subutilização dos recursos urbanos dentro da cidade consolidada; por outro lado, um panorama de demanda não satisfeita nos conjuntos localizados nos limites da cidade. 
Embora os conjuntos habitacionais não sejam exemplos de autoconstrução, a política de habitação social, nesses casos, oferece espaços que costumam apresentar equipamentos e estruturas escassas e de baixa qualidade. O translado desde essas verdadeiras cidades periféricas aos lugares de trabalho ou de estudo implica em investimentos de tempo e dedicação de boa parte dos poucos recursos financeiros ao pagamento dos mesmos, além das implicações sobre o convívio familiar e sobre o nível de vulnerabilidade derivado do isolamento espacial (Arango, 2014; Ramírez; Ziccardi, 2008; Hidalgo et al, 2007).

Além destas limitações, a habitação de interesse social, em sua forma mercantilizada, apresenta restrições de acesso devido à exigência de solvência garantida por uma capacidade de pagamento regular capaz de viabilizar o crédito. Deste modo, os programas baseados na concessão de subsídios excluem os grupos mais afetados pelos déficits habitacionais que são os setores de nível de renda mais baixos e instáveis.

A habitação de interesse social conta com um sistema de financiamento inacessíveis aos grupos de renda mais baixos (a população subempregada ou desempregada) que são os maiores afetados pelos déficits habitacionais. Ou seja, esses grupos não se adequam a nenhum dos mercados habitacionais, público ou privado (Moctezuma, 2017; Coulomb, 2015; Jaramillo, 2008; Parias, 2008; Vidal-Koppmann, 2007). Na medida em que esta política não atua sobre o público mais vulneráveis, que continua encontrando a solução imediata nos processos de autoconstrução e na informalidade.

Diversas experiências comuns a distintas partes de América Latina observam que os subsídios ao consumidor como alternativa para viabilizar o acesso aos conjuntos habitacionais não chegam a cobrir uma parte importante da demanda. Salazar (2012) expõe experiências, a título de exemplos: em Colômbia, a expansão do mercado informal se apresentou na era dos subsídiose em México, o espetacular aumento da oferta habitacional formal privada não freou as formações irregulares, se não, houve o contrário (Connolly, 2013). Em Buenos Aires, durante os anos 2000, apesar das taxas de crescimento econômico, da existência de legislação que habilitou a regulação da propriedade nos bairros e de um gasto público considerável em habitação social, a informalidade continua crescendo (Van Gelder, et al, 2013).

As políticas de habitação social combinam fenômenos de expansão da mancha urbana (atuando sobre os municípios metropolitanos e reforçando o cenário de fragmentação espacial) que tão pouco conseguem enfrentar a dimensão dos assentamentos informais. As condições habitacionais mantêm padrões de precariedade (guardando semelhanças de precariedade em relação à cidade informal, exposto, especialmente, ao longo do tempo), apesar do uso de mecanismos industrializados e de produção em grande escala. 


\section{CONSIDERAÇÕES FINAIS}

Este artigo traz uma revisão de literatura estabelecendo os links entre a pobreza urbana e a estruturação dos habitats dos pobres em cidades da região latino-americana. $\mathrm{O}$ trabalho se centrou na exposição dos elementos oferecidos pela literatura regional, onde a principal expressão dos espaços de pobreza são os assentamentos informais. Os processos produtivos marcados pela dependência externa e por uma extrema desigualdade social estruturaram as cidades da Região. As consequências espaciais foram registradas pela vasta extensão das manchas urbanizadas, pelas macrocefalias urbanas e pelo protagonismo do mercado imobiliário no desenvolvimento das cidades. Os elevados níveis de déficits habitacionais e o acesso desigual à terra, aos serviços e aos equipamentos urbanos são marcas registradas de seus espaços urbanos.

A natureza espontânea e improvisada das ocupações do solo estruturou o fenômeno da cidade informal que, devido à sua dimensão, se converteu em um panorama da urbe latinoamericana. Estes espaços surgem a partir da necessidade dos grupos que não podem ter acesso ao mercado imobiliário formal. A falta de recursos monetários, a existência de terras ociosas e os comportamentos permissivos do Estado motivaram a formação e a consolidação deste modelo de urbanização, onde os conceitos de "urbanização inversa" ou "urbanização sem infraestruturas" se utilizam para designar os processos de ocupação e de consolidação destes espaços. A cidade informal, embora não se caracterize como um território totalmente homogêneo socioeconomicamente, se consolidou como um espaço propicio à manutenção do ciclo de pobreza, exclusão e de marginalidade urbana.

Diante deste contexto, duas políticas urbanas se destacam com relação aos assentamentos informais: os programas de melhoramento de bairros e os projetos de habitação social. Os projetos de melhoramento de bairros contam o apoio de instituições internacionais e embora tenham gerado resultados positivos sobre a qualidade de vida e a integração à cidade formal, a ausência de normativas de proteção aos moradores vem fomentando processos de gentrificação e o surgimento de novos espaços informais protagonizados pelos próprios beneficiários da ação política.

Por outro lado, as alternativas de urbanização centradas na habitação social localizadas em grandes conjuntos habitacionais em áreas periféricas se constituem como um elemento especialmente problemático para as cidades, tanto devido aos déficits de infraestrutura como pela concentração acumulada de elementos sociológicos negativos, se convertendo em uma espécie de assentamento informal urbanizado. Adicionalmente, estes espaços costumam se localizar longe dos centros, no qual, a ausência de oportunidades é agravada pela localização periférica, longe dos núcleos de emprego com implicações sobre a coesão social e sobre o modelo de crescimento urbano extenso, disperso e fragmentado. 
As ações se mostram sumamente importantes à medida que se tratam de intervenções públicas com impactos positivos sobre a qualidade de vida nos hábitats dos mais pobres, não obstante, as experiências latino-americanas evidenciam as limitações da ação pública que comprometem a sustentabilidade e a efetividade da política no sentido de cumprir com o objetivo de reduzir a vulnerabilidade urbana dos moradores de assentamentos informais, necessitando, por tanto, serem revistas em seus pontos mais frágeis.

\section{REFERENCIAS BIBLIOGRÁFICAS}

AARON G, P. El mètode URBAN i la sevadifusiócom a principal valor afegit. en (re) construcción, necessitatssocials, transformació i millora de barris. Col.lecció_EstudisSèrie_Territori, 5. Barcelona. Generalitat de Cataluña. (2008).

ABRAMO, P. El mercado del suelo informal en favelas y la movilidad residencial de los pobres en las grandes metrópolis: un objeto de estudio para América Latina. Bogotá. Revista Territorios, (18-19). (2008).

AGUILAR, A. G., \& LÓPEZ, F. M. Espacios de pobreza en la periferia urbana y suburbios interiores de la Ciudad de México: Las desventajas acumuladas. Santiago.Revista EURE 42(125), 5-29. (2016).

ARANGO, A. La sensación de inseguridad: Calles cerradas en conjuntos habitacionales periurbanos de la ciudad de México. Scripta Nova. Revista Electrónica de Geografía y Ciencias Sociales, 18. (2014).

AVENDAÑO, F. Q. Imaginarios urbanos, espacio público y ciudad en América Latina. Madrid. Pensar Iberoamérica: Revista de cultura, (8), 3. (2006).

BAYÓN, M. C.La integración excluyente. Experiencias, discursos y representaciones de la pobreza urbana en México,México. DF, UNAM-IIS / Bonilla Artigas Editores. (2015).

BRICEÑO-LEÓN, R Libertad para alquilar. El mercado informal de vivienda de Caracas. Bogotá. Revista Territorios, (18-19), 103-127. (2008).

BOILS, M, G. Segregación y modelo habitacional en grandes conjuntos de vivienda en México. Cordera, Rolando et al. Pobreza, desigualdad y exclusión social en la ciudad del siglo XXI. México. DF. Siglo XXI Editores, México. (2008).

BOURDIEU, P.“Efectos de lugar”. En La miseria del mundo, dirección de Pierre Bourdieu. Buenos Aires: Fondo de Cultura Económica. (2002).

CAMARGO, A. P. S, \& HURTADO, A. T.Informalidad del siglo XXI. Características de la oferta informal de suelo $y$ vivienda en Bogotá durante la primera década del siglo XXI. Bogotá. Revista Territorios, (27). (2012).

CLICHEVSKY, N. Informalidad y regularización del suelo urbano en América latina.Algunasreflexiones. Rio de Janeiro. Revista Brasileira de Estudos Urbanos e Regionais, 9(2).(2007).

Pobreza y acceso al suelo urbano: Algunas interrogantes sobre las políticas de regularización en América Latina (Vol. 75). UnitedNationsPublications. (2003).

CONNOLLY, P. La ciudad y el hábitat popular: paradigma latinoamericano.México. DF. B. Ramírez V. \& E. Pradilla C.(Comps.), Teorías sobre la ciudad en América Latina, 505-562. (2013).

COSSIO, B. E., \& TOURN, G. M. Viviendas y territorio. El rol del estado en la organización territorial urbana. Scripta Nova: revista electrónica de geografía y ciencias sociales, 9. (2005).

COULOMB, R. B. Las políticas de vivienda de los estados latinoamericanos.México. DF. B. Ramírez V. \& E. Pradilla C, Teorías sobre la ciudad en América Latina, 563-616. (2015).

CRAVINO, M. C. Relaciones entre el mercado inmobiliario informal y las redes sociales en asentamientos informales del área metropolitana de Buenos Aires.Bogotá. Revista territorios, (18-19). (2008).

CRUZ-MUÑOZ, F., \& ISUNZA, G. Construcción del hábitat en la periferia de la Ciudad de México: Estudio de caso en Zumpango. Santiago. RevistaEURE, 43(129), 187-207. (2017).

REVISTA ECONOMIA POLÍTICA DO DESENVOLVIMENTO $\quad$ Maceió - AL $\quad$ V.5 N.7. $\quad$ JUNHO/2018 $\quad$ P.1-21 Página-19


DAVIS, M. Planet of Slums. New York: Verso. (2006).

DI VIRGILIO, M. M. Urbanizaciones de origen informal en Buenos Aires. Lógicas de producción de suelo urbano y acceso a la vivienda.México. DF. Estudios demográficos y urbanos de El Colegio de México, 30(3), 651-690. (2015).

DI VIRGILIO, M. M., ARQUEROS, M. M. S., \& GUEVARA, T. Estrategias de acceso al suelo ya la vivienda en barrios populares del Área Metropolitana de Buenos Aires. Revista Brasileira de Estudos Urbanos e Regionais, 14(1). (2012).

DONAT, C. La segregación urbana: marco teórico-conceptual y estado de la cuestión. Ub. Barcelona. (2018).

DUHAU, E. La división social del espacio metropolitano. Buenos Aires. Nueva Sociedad, 243(79), e91. (2013).

GARZA, G. Mercado formal e informal de suelo. Análisis de ocho ciudades.México. DF. Estudios demográficos y urbanos, vol. 27, núm. 3 (81), 853-861. (2012).

GOERLICHO, F.J.G. El empobrecimento valenciano. InstitucióAlfons el Magnànim- CVEI. Diputació de València. Valencia. (2017).

HIDALGO, R., ZUNINO, H., \& ÁLVAREZ, L. EI emplazamiento periférico de la vivienda social en el área metropolitana de Santiago de Chile: consecuencias socio espaciales y sugerencias para modificar los criterios actuales de localización. Scripta Nova, 11(245), 27. (2008).

HERNÁNDEZ, M. T. E., PÉREZ, E. M., \& BORJA, J. C. La promoción privada y los grandes conjuntos habitacionales: nuevas modalidades de acceso a la vivienda. Scripta Nova: revista electrónica de geografía y ciencias sociales, 9.(2005).

HERNÁNDEZ, E., MANZUR, D., TREVIÑO, R., \& COBOS, R. Asentamientos marginales resultado del poder local para el control socio-político en la Zona Metropolitana de Tampico, Tamaulipas, México. Scripta Nova Revista Electrónica de Geografía y Ciencias Sociales: 18 (493). (2014).

IGLESIAS, B. M., \& SÁNCHEZ, D. (2013). Ciudadanía informacional: gobernanza inclusiva en la ciudad informal/Informationalcitizenship: inclusive governance in the informal city.Barcelona. Revista CIDOB d'afersinternacionals, 19-44. (2007).

JAMARILLO, S, G. Reflexiones sobre la "informalidad" fundiaria como peculiaridad de los mercados del suelo en las ciudades de América Latina. Revista Territorios, 18. (2008).

JANOSCHKA, M. El nuevo modelo de la ciudad latinoamericana: fragmentación y privatización.Santiago. Revista EURE, 28(85), 11-20. (2002).

LAZO, A., \& CALDERÓN, R. Los anclajes en la proximidad y la movilidad cotidiana: Retrato de tres barrios de la ciudad de Santiago de Chile.Santiago. EURE, 40(121), 121-140. (2014).

LUNECKE, A. Inseguridad ciudadana y diferenciación social en el nivel microbarrial: el caso del sector Santo Tomás, Santiago de Chile. Santiago. EURE, 42(125), 109-129. (2016).

MAGLIANO, M. J., PERISSINOTTI, M. V., \& ZENKLUSEN, D. Estrategias en torno a las formas de apropiación y organización del espacio en un" barrio de migrantes" de la ciudad de Córdoba, Argentina.Buenos Aires. Estudios demográficos y urbanos, 29(3), 513-540. (2014).

MARICATO, E. O Estatuto da cidade periférica in O Estatuto da Cidade comentado.São Paulo. Ministério das Cidades.(2010).

Metrópole, legislação e desigualdade. Santiago. Estudios avanzados,17(48), 151-166. (2003).

MATOSSIAN, B. Expansión urbana y migración. El caso de los migrantes chilenos en San Carlos de Bariloche como actores destacados en la conformación de barrios populares. Scripta Nova, 14(331), 76. (2010).

MIRANDA, V, G. El hábitat popular. Algunos aportes teóricos de la realidad habitacional de sectores desposeídos. Bogotá. Revista Territorios, (36), 217-238. (2017).

MOCTEZUMA, V, M. Experiencia y significados simbólicos de los habitantes de conjuntos urbanos de interés social en México: segregación, diferencia y distinción.México. DF. Estudios demográficos y urbanos, 32(3), 487-514. (2017).

MONAYAR, V. Informalidad urbana $\mathbf{y}$ acceso al suelo. Acciones $\mathbf{y}$ efectos de la política habitacional en la ciudad de Córdoba-Argentina.Bogotá. Revista Territorios, (24). (2011). 
MORALES, E. J. L. Impacto del crecimiento del Gran Santiago en el deterioro funcional de sus espacios pericentrales. Scripta Nova: revista electrónica de geografía y ciencias sociales, 9. (2005).

O.N.U. HÁBITAT.Estado de las ciudades de América Latina y el Caribe 2012. Rumbo a una nueva transición urbana. Brasil: Programa de las Naciones Unidas para los asentamientos humanos. (2012).

PARIAS, A, D. El mercado de arrendamiento en los barrios informales en Bogotá, un mercado estructural.Bogotá. Revista Territorios, (18-19). (2008).

PASTERNAK, S. T. “O Brasil e suas Favelas”. In: Abramo, Pedro (Org.). A cidade da Informalidade: O desafio das cidades Latino-americanas. Rio de Janeiro: Editora Sette Letras, pp. 13-42. (2003).

PERLMAN, J. Marginalidade: do mito à realidade nas favelas do Rio de Janeiro.Rio de Janeiro. Prefeitura do Rio, Estudos, (102). (2003).

PÍREZ, P. Las heterogeneidades en la producción de la urbanización y los servicios urbanos en América Latina. Bogotá. Revista Territorios, (34), 87-112. (2016).

La urbanización y la política de los servicios urbanos en América Latina.México. DF. Revista Andamios. Volumen 10, número 22, mayo-agosto, pp. 45-67. (2013).

RAMÍREZ, P., \& ZICCARDI, A. Pobreza urbana, desigualdad y exclusión social en la ciudad del siglo XXI, una introducción. Cordera, Rolando; Ramirez, Patricia; y Ziccardi, Alicia (Coordinadores. 2008). Pobreza, Desigualdad y exclusión social en la ciudad del siglo XXI. México. DF: Siglo XXI. (2008).

REICH, R. B. Supercapitalism: Thetransformation of business, democracy, and everydaylife.Westminster.Vintage. (2008).

SALAZAR, C. E. (Ed.). Irregular: suelo y mercado en América Latina. México DF. El Colegio de Mexico AC. (2012).

SMOLKA, M. Informalidad, pobreza urbana y precios de la tierra. Cambridge. LandLines, 15(1), 135. (2003).

TARDIN, R. La ciudad informal. Las otras geografías. Valencia. Editorial Tirant lo Blanch, 389-404. (2006).

VAN GELDER, J. L., CRAVINO, M. C., \& OSTUNI, F. Movilidad social espacial en los asentamientos informales de Buenos aires.Rio de Janeiro. Revista Brasileira de Estudos Urbanos e Regionais, 15(2).(2013).

VIDAL-KOPPMANN, S. La expansión de la periferia metropolitana de Buenos Aires. "Villas miseria" y "countries": de la ghettización a la integración de actores en el desarrollo local urbano. Scripta Nova. Revista Electrónica de Geografía y Ciencias Sociales, 11. (2007).

WACQUANT, L. Parias urbanos. Marginalidad en la ciudad a comienzos del milenio. Buenos Aires. Manantial.Ed. 4. (2015).

Los condenados de la ciudad. Gueto, periferias y Estado. Buenos Aires. Editorial Siglo XXI. (2007).

Whatis a ghetto? Building a sociological concept. Curitiba. Revista de Sociologia e Política, (23), 155-164. (2004).

WINCHESTER, L. La dimensión económica de la pobreza y precariedad urbana en las ciudades latinoamericanas: Implicaciones para las políticas del hábitat. Santiago. Revista EURE, 34(103), 27-47. (2008).

ZICCARDI, A. Pobreza y exclusión social en las ciudades del siglo XXI.ZICCARDI, Alicia Procesos de urbanización de la pobreza y nuevas formas de exclusión social. Los retos de las políticas sociales de las ciudades latinoamericanas del siglo XXI. Bogotá: Siglo del Hombre Editores. (2008). 